\title{
Expression of a Cleaved Brain-Specific Extracellular Matrix Protein Mediates Glioma Cell Invasion In Vivo
}

\author{
Hong Zhang, Gail Kelly, Cynthia Zerillo, Diane M. Jaworski, and Susan Hockfield \\ Section of Neurobiology, Yale University School of Medicine, New Haven, Connecticut 06520-8001
}

Malignant gliomas (primary brain tumors) aggressively invade the surrounding normal brain. This invasive ability is not demonstrated by brain metastases of nonglial cancers. The brainspecific, brain-enriched hyaluronan binding (BEHAB)/brevican gene, which encodes an extracellular hyaluronan-binding protein, is consistently expressed by human glioma and is not expressed by tumors of nonglial origin (Jaworski et al., 1996). $\mathrm{BEHAB} /$ brevican can be cleaved into an $\mathrm{N}$-terminal fragment that contains a hyaluronan-binding domain (HABD) and a C-terminal fragment (Yamada et al., 1995). Here, using antisera to peptides in the predicted N-terminal and C-terminal proteolytic fragments, we demonstrate that the BEHAB/brevican protein is cleaved in invasive human and rodent gliomas. A role for this protein in glioma cell invasion was tested by transfecting a noninvasive cell line with the BEHAB/brevican gene. The non- invasive 9L glioma cell was transfected with either full-length $\mathrm{BEHAB/brevican}$ or the HABD and tested for invasion in in vitro and in vivo invasion assays. Although both constructs increased invasion in vitro, only the HABD increased invasion by tumors growing in vivo. Experimental intracranial tumors from full-length transfectants showed no increase in invasion over control tumors, whereas tumors from HABD transfectants showed a marked potentiation of tumor invasion, producing new tumor foci at sites distant from the main tumor mass. This work demonstrates a role for a brain-specific extracellular matrix protein in glioma invasion, opening new therapeutic avenues for a uniformly fatal disease.

Key words: glioma; brain tumor; astrocytoma; tumorogenesis; motility; proteoglycan; BEHAB; brevican; invasion; extracellular matrix
Primary tumors of the CNS (gliomas) are notoriously difficult to control, attributable in large measure to their highly invasive behavior. The ability to invade into the surrounding normal brain is essentially a property unique to primary brain tumor cells; nonglial tumor cells that metastasize to brain, such as those originating from primary tumors elsewhere (e.g., breast or lung), grow as circumscribed masses with well-defined borders. The composition of the extracellular matrix may be a critical factor in determining the invasive potential of cancer cells, such that the production of matrix elements by glioma cells might mediate their invasion into normal tissue.

The composition of the extracellular matrix of the brain changes over the course of development (Herndon and Lander, 1990; Hockfield, 1990; Sheppard et al., 1991). Behaviors characteristic of cells in the developing brain, such as cell proliferation and migration, neuronal and glial process outgrowth, and the elaboration of the capillary network, take place in a soluble matrix that is permissive for cell movement. In contrast, there is

\footnotetext{
Received Nov. 10, 1997; revised Jan 13, 1998; accepted Jan. 15, 1998.

This work was supported by National Institutes of Health Grants EY06511 and NS35228 to S.H. We thank our colleagues for their generosity in supplying reagents that were central to this work: Dr. William Hickey for the CNS-1 cell line, Dr. Fred Gage for the 9L gliosarcoma cell line, Dr. Thom Hughes for the GFP construct, and Dr. Yu Yamaguchi for the full-length BEHAB/brevican construct. We also thank Drs. E. D. Gundelfinger and C. Seidenbecher for antisera to BEHAB/brevican, which were used in preliminary experiments, and Drs. Sydney Gary and Cynthia Lander for critically reviewing this manuscript. We also acknowledge our ongoing collaboration in this work with Drs. Joseph Piepmeier, Thomas Byrne, and Veronica Chang.

Correspondence should be addressed to Dr. Susan Hockfield, Section of Neurobiology, Yale University, 333 Cedar Street, SHM C-405, New Haven, CT 06510-8001.

Dr. Jaworski's present address: Department of Anatomy and Neurobiology, University of Vermont School of Medicine, Burlington, VT 05405.

Copyright (C) 1998 Society for Neuroscience $0270-6474 / 98 / 182370-07 \$ 05.00 / 0$
}

little cell motility in the normal mature brain. The matrix of the mature brain is relatively insoluble compared with that of the immature brain and can stabilize mature cell-cell relationships (Hockfield et al., 1990). A return to an immature, more soluble matrix during tumor growth could facilitate tumor cell motility and angiogenesis.

We recently cloned the gene for a brain-specific extracellular matrix protein, BEHAB (brain-enriched hyaluronan binding) (Jaworski et al., 1994), which was independently cloned in another laboratory and named brevican (Yamada et al., 1994). $\mathrm{BEHAB} /$ brevican encodes a member of the proteoglycan tandem-repeat family of proteins, and its predicted product is a secreted protein with a hyaluronan-binding domain (HABD) (Jaworski et al., 1994; Yamada et al., 1994). A GPI-anchored isoform of this protein has also been reported (Seidenbecher et al., 1995). The BEHAB/brevican gene is expressed at high levels during the period when glial cells, which give rise to primary brain tumors, are first born (Jaworski et al., 1995). BEHAB/ brevican is also expressed in tumors derived from glial cells (HABD) (Jaworski et al., 1996). In every one of over 40 surgical samples of human glioma assayed to date, including oligodendroglioma, all grades of astrocytoma, and gliosarcoma, BEHAB/ brevican mRNA is detected. By contrast, BEHAB/brevican is undetectable in tumors that are not of glial origin, including CNS lymphoma, meningioma, and carcinomas of the lung, colon, and breast, in either primary locations or as metastases to the brain. Importantly, BEHAB/brevican is expressed at very low levels in the normal adult human brain and in brain samples from individuals with noncancer neuropathologies (Jaworski et al., 1996). In rodent brain tumor models, glioma cell lines that reproduce the invasive behavior characteristic of human glioma express BE$\mathrm{HAB} /$ brevican mRNA, whereas glioma cell lines that grow non- 
invasively do not express it (Jaworski et al., 1996). The expression in invasive tumors, together with the predicted structure of the protein, suggests that BEHAB/brevican plays a role in glioma cell invasion.

Here, BEHAB/brevican antibodies have been used to study the expression of the protein in invasive human and rodent brain tumors. We show that in these tumors, BEHAB/brevican is cleaved into an $\mathrm{N}$-terminal fragment containing the hyaluronanbinding domain (HABD) and a C-terminal fragment. To test for a role for $\mathrm{BEHAB} /$ brevican in tumor invasion, we transfected a noninvasive glioma cell line with either the full-length BEHAB/ brevican gene or with a construct encoding the $\mathrm{N}$-terminal HABD. Although both constructs increase invasion in vitro, in both a Matrigel invasion assay and a motility assay, only the HABD fragment increases the invasion of experimental tumors in vivo. These results offer an explanation for the unusual invasive ability of brain tumor cells and identify new therapeutic targets for a uniformly fatal disease.

\section{MATERIALS AND METHODS}

Cell transfections. 9L gliosarcoma cells were transfected either with a full-length cDNA encoding the secreted form of rat BEHAB/brevican (generously provided by $\mathrm{Dr}$. Yu Yamaguchi, Burnham Institute) (Yamada et al., 1995) or with a $1.1 \mathrm{~kb}$ cDNA (nucleotides 60-1172 of the full-length clone) encoding the HABD of BEHAB/brevican by either calcium phosphate coprecipitation or electroporation. The cDNAs were cloned into the EcoRI site of the eukaryotic expression vector pCDNA3 (Invitrogen, San Diego, CA). Transfectants were selected in DMEM with $10 \%$ fetal bovine serum (FBS) and $1 \mathrm{mg} / \mathrm{ml} \mathrm{G} 418$. After 10 to $14 \mathrm{~d}$, G418-resistant colonies were isolated and assayed for BEHAB/brevican or HABD expression by RNase protection and Northern blot. Transfectants expressing an appropriately sized mRNA that hybridized with a $\mathrm{BEHAB} /$ brevican-specific probe were subcloned and used for further studies. As a control, 9L cells were transfected with the pCDNA3 vector containing a cDNA insert encoding green fluorescent protein (GFP) (generously provided by Dr. Thom Hughes, Yale University). Stable transfectants were maintained in DMEM with $10 \%$ FBS and $500 \mu \mathrm{g} / \mathrm{ml}$ G418. The rat CNS-1 glioma cell line was maintained in RPMI with $10 \%$ FBS.

Western blot analysis. Five milliliters of OPTI-MEM (Life Technologies) with $1 \%$ FBS were added to cultures when cells reached $80 \%$ confluence on $100 \mathrm{~mm}$ culture plates. After $48 \mathrm{hr}$, conditioned medium was collected, and cell debris was removed by centrifugation. For cell homogenates, cultures were rinsed in Dulbecco's PBS (DPBS; Life Technologies) with a cocktail of protease inhibitors (Boehringer Mannheim, Indianapolis, IN), and cells were collected by scraping. For tumor samples, tissues were homogenized in DPBS with protease inhibitors. Samples were electrophoresed on either 8 or $10 \%$ SDS-polyacrylamide gels, and proteins were then electrophoretically transferred to nitrocellulose. Blots were incubated with specific rabbit primary antisera (see below), followed by alkaline phosphatase-conjugated goat anti-rabbit IgG secondary antibodies (Promega, Madison, WI). Immunoreactive bands were visualized with nitro blue tetrazolium and 5-bromo-4-chloro-3indolyl phosphate (Sigma, St. Louis, MO).

Matrigel invasion assay. To study the invasive ability of tumor cells, we performed an in vitro Matrigel assay (Mohanam et al., 1993). Briefly, 100 $\mu \mathrm{l}$ of a Matrigel solution (Collaborative Research, Bedford, MA; 1 $\mathrm{mg} / \mathrm{ml}$ in DMEM) was placed on a Transwell insert (Costar, Cambridge, $\mathrm{MA} ; 12 \mathrm{~mm}, 8 \mu \mathrm{m}$ pore size) and allowed to gel at $37^{\circ} \mathrm{C}$ for $30-40 \mathrm{~min}$. Tumor cells were suspended in medium $(100$ cells $/ \mu 1$ of DMEM with $10 \%$ FBS), and $100 \mu \mathrm{l}$ aliquots were added to each Matrigel-coated Transwell insert. The lower chamber of the Transwell was filled with 500 $\mu \mathrm{l}$ of DMEM with $10 \%$ FBS to which either fibronectin $(5 \mu \mathrm{g} / \mathrm{ml})$ or hyaluronan (HA) $(200 \mu \mathrm{g} / \mathrm{ml})$ was added as a chemoattractant. Either 18 or $6 \mathrm{hr}$ later, cultures were fixed in acid alcohol and stained with Coomassie blue $(0.1 \%$ in $50 \%$ methanol with $7.5 \%$ acetic acid). Cells on the upper side of the insert membrane were removed with a cotton swab, and the number of cells that had migrated to the lower side of the membrane was counted. For each membrane, eight random fields were selected, and the number of cells was counted on an inverted microscope using a $20 \times$ objective lens.
Transwell motility assay. The assay was performed essentially as described for the Matrigel assay (above), with the exception that the Transwell insert was uncoated. Tumor cells $(10,000$ cells/well) were applied to the Transwell membrane, and the lower chamber was filled with medium (DMEM with $10 \%$ FBS, supplemented with HA at 200 $\mu \mathrm{g} / \mathrm{ml})$. Six hours later, cultures were processed and analyzed as described above for the Matrigel assay.

Antibodies. Rabbit antisera to BEHAB/brevican were generated to a peptide in the HABD (amino acids 253-279, DLNGELFLGAPPGKLTWEEARDYCLER) or to a peptide in the C-terminal fragment (amino acids 506-529, SPSPRPPRVHGPPAETLQPPREGS). Antisera were affinity-purified, and specific immunoreactivity was confirmed by blocking with specific peptides.

Intracranial grafts. Intracranial grafts were performed as described previously (Jaworski et al., 1996). Briefly, cell suspensions were prepared in complete PBS (PBS supplemented with $1 \mu \mathrm{g} / \mathrm{ml} \mathrm{MgCl}_{2}$ and $\mathrm{CaCl}_{2}$ and $0.1 \%$ glucose) at $1-5 \times 10^{4}$ cells $/ \mu$ l. Using a Hamilton syringe, we injected stereotaxically $3 \mu \mathrm{l}$ of the cell suspension over a $4-5$ min period into the thalamus of a postnatal day 45 rat (Lewis for CNS-1 cells; Fischer 344 for 9L-transfected cell lines). Ten to fifteen days after the injection, the rats were killed, and the brains were quickly frozen on dry ice. Each brain was sectioned at $20 \mu \mathrm{m}$ onto gelatin-subbed slides, and the sections were stained with cresyl violet to visualize tumor cells. Sections were also stained with an antibody to nestin (monoclonal antibody Rat-401) (Hockfield and McKay, 1985) that recognizes glioma cells. An identical distribution of tumor cells was seen in sections stained with either cresyl violet or Rat-401. Images of random sections through each tumor were captured on a computer. Using the National Institutes of Health Image program, we determined the border of the tumor with the underlying thalamus, and the number of cell clusters at distances of $0.5-1$ $\mathrm{mm}$ and over $1 \mathrm{~mm}$ from the tumor border was counted in each section. The statistical analyses incorporated one random section from each of several independent tumors $(n=6$ independent tumors for 9L-GFP; $n=$ 12 for 9L-BEHAB/brevican; and $n=14$ for 9L-HABD).

Statistical analyses. All statistical analyses were performed using the Student's $t$ test; the level of significance was set at $p<0.01$.

\section{RESULTS}

To begin our studies to determine whether BEHAB/brevican might play a role in tumor invasion, we assayed protein expression in rodent and human brain tumors. Experimental brain tumors established from the rat CNS-1 and 9L glioma cell lines, when implanted as intracranial grafts in syngeneic hosts, show two different patterns of growth (Jaworski et al., 1996). Intracranial grafts of the 9L gliosarcoma line display properties characteristic of brain metastases of peripheral tumors, in that they do not express BEHAB/brevican mRNA and they grow as well-defined cell masses that do not invade the surrounding brain tissue. In marked contrast, intracranial grafts of the CNS-1 glioma cell line display properties characteristic of human glioma, in that they express BEHAB/brevican mRNA and grow invasively. To study the protein product of the $\mathrm{BEHAB} /$ brevican mRNA, we examined $\mathrm{BEHAB} /$ brevican protein expression in experimental rodent brain tumors. Tumors established from the 9L cell line do not express BEHAB/brevican protein. In contrast, Western blots of brain tumors established from CNS-1 cells show three major immunoreactive bands (Fig. $1 A$ ). The $140 \mathrm{kDa}$ band represents full-length BEHAB/brevican, and the 90 and $50 \mathrm{kDa}$ bands represent $\mathrm{C}$ - and $\mathrm{N}$-terminal cleavage products, respectively, from a predicted, conserved proteolytic site (Yamada et al., 1995). The 140 and $90 \mathrm{kDa}$ forms correspond to the 140 and 80 kDa bands reported previously (Seidenbecher et al., 1995; Yamada et al., 1995). Surgical samples of human gliomas were also analyzed by Western blotting, and these, like the invasive rodent tumors, showed both full-length and cleaved protein products of the BEHAB/brevican gene (Fig. $1 B$ ) that were of slightly greater apparent molecular mass. 
A

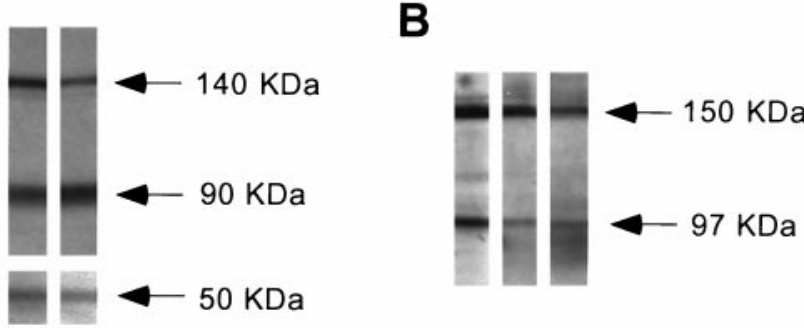

Figure 1. Expression of BEHAB/brevican in rodent and human brain tumors. $A$, Western blots of invasive rodent brain tumors established from CNS-1 cells show full-length $140 \mathrm{kDa} \mathrm{BEHAB} /$ brevican, as well as 90 and $50 \mathrm{kDa}$ proteolytic fragments. Full-length and cleaved $90 \mathrm{kDa}$ bands are visualized with an antibody to a peptide in the C-terminal portion of $\mathrm{BEHAB} /$ brevican; the $50 \mathrm{kDa}$ band is visualized with an antibody to a peptide in the $\mathrm{N}$-terminal portion of $\mathrm{BEHAB} /$ brevican (see Materials and Methods). $B$, Western blots of surgical samples from neuropathologically diagnosed glioblastoma multiforme show $150 \mathrm{kDa}$ full-length BEHAB/ brevican and a $97 \mathrm{kDa}$ proteolytic fragment. These bands are immunoreactive with the antibody to the $\mathrm{C}$-terminal peptide; however, the antibody to the $\mathrm{N}$-terminal peptide does not recognize the human protein.

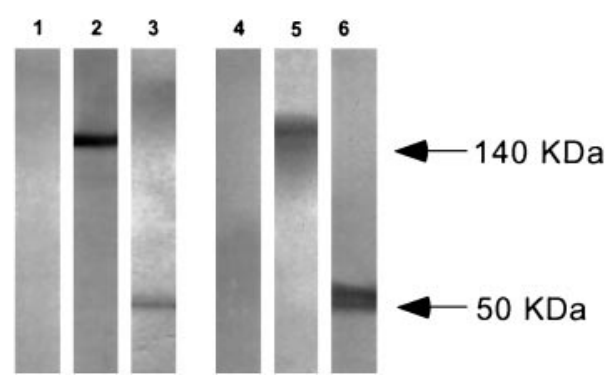

Figure 2. Transfected 9L cells express full-length BEHAB/brevican or the HABD. Western blots of cell homogenates (lanes 1-3) and conditioned media (lanes 4-6) are from transfected cells. 9L-GFP cell homogenates (lane 1) and conditioned media (lane 4) show no immunoreactivity for $\mathrm{BEHAB} /$ brevican or its cleavage products. $9 \mathrm{~L}-\mathrm{BEHAB} /$ brevican cell homogenates (lane 2) and conditioned media (lane 5) contain a 140 kDa-immunoreactive species. 9L-HABD cell homogenates (lane 3) and conditioned media (lane 6) contain a $50 \mathrm{kDa}$ species. The immunoreactive species in conditioned media from both $9 \mathrm{~L}-\mathrm{BEHAB} /$ brevican and 9L-HABD transfectants are polydisperse (lanes 5,6 ), possibly reflecting glycosylation.

To test whether BEHAB/brevican mediates invasion, we established stable transfectants of the noninvasive 9L gliosarcoma cell line. One set of transfectants, 9L-BEHAB/brevican, carried a construct encoding full-length BEHAB/brevican (amino acids 1-883), and a second set, 9L-HABD, carried a construct encoding the N-terminal HABD (amino acids 1-371), which corresponds approximately to the $50 \mathrm{kDa}$ cleavage product. 9L cells transfected with the gene for the GFP served as a control (9LGFP). Expression of appropriate mRNA was demonstrated by RNase protection and Northern blot analyses (data not shown). Western blot analysis confirmed the expression of the predicted proteins (Fig. 2). 9L-GFP transfectants showed no BEHAB/ brevican immunoreactivity, whereas cell homogenates of 9LBEHAB/brevican and 9L-HABD transfectants exhibited a 140 $\mathrm{kDa}$ - and a $50 \mathrm{kDa}$-immunoreactive species, respectively. Both 9L-BEHAB/brevican and 9L-HABD transfectants secreted the encoded proteins into the medium in which they were maintained (Fig. 2, lanes 5, 6). The secreted proteins were more disperse and slightly larger in apparent molecular mass, most likely because of glycosylation. Immunoreactivity on Western blots of both 9L-
BEHAB/brevican and 9L-HABD transfectants was blocked by specific, but not by irrelevant, peptides (data not shown).

Transfected cells were first tested for invasive ability using the Matrigel in vitro invasion assay (Albini et al., 1987; Merzak et al., 1994). Eighteen hours after plating onto Matrigel-coated Transwell inserts, the number of cells that had migrated through the Matrigel to the bottom of the filter was counted (Fig. $3 A$ ). Two independent lines from each construct were assayed. 9L-GFP transfectants showed little migration under any condition tested. Both 9L-BEHAB/brevican and 9L-HABD transfectants showed a marked increase in invasive ability over that seen with the control 9L-GFP cells. There was no statistically significant difference between the invasive capacity of $9 \mathrm{~L}-\mathrm{BEHAB} /$ brevican and 9L-HABD transfectants. Invasion through Matrigel was assayed using both fibronectin and hyaluronan as attractants in the lower chamber of the Transwell apparatus, and there was no difference in the response of either cell type to the different attractants. When the Matrigel assay was performed using a $6 \mathrm{hr}$ incubation period, similar results were found; 9L-BEHAB/brevican and 9L-HABD cells showed equivalent increases in invasiveness over 9L-GFP cells (data not shown).

To eliminate the possibility that the full-length $\mathrm{BEHAB} /$ brevican was cleaved by proteases in the Matrigel, two experiments were performed. First, heat-inactivated Matrigel $\left(56^{\circ} ; 1 \mathrm{hr}\right)$ was used for the invasion assay, which gave identical results to those described above. Second, another motility assay was performed that did not require Matrigel. We performed a standard cell motility assay using a Transwell apparatus (Koochekpour et al., 1995); cells were plated onto the Transwell inserts without any Matrigel coating. Six hours later, the number of cells that migrated to the lower side of the insert membrane was counted. In the absence of Matrigel, both 9L-BEHAB/brevican and 9LHABD cells showed a marked increase in motility over 9L-GFP cells (Fig. 3B). As seen in the Matrigel invasion assay, there was not a significant difference between the motility of cells expressing either the full-length or the HABD protein.

Matrigel provides a reproducible, uniform matrix; however, its composition is quite different from that of the extracellular matrix of brain. Matrigel and the extracellular matrix of most tissues contain collagen, laminin, and fibronectin, constituents that are lacking or present at extremely low abundance in the extracellular matrix of the adult brain (Lander and Hockfield, 1998). Therefore, cell migration through Matrigel may not accurately reflect the ability of cells to invade within the matrix of the brain. To test the ability of BEHAB/brevican to mediate invasion in situ, we used an in vivo brain tumor invasion model. Transfected 9L cells were injected into the diencephalon of adult rats. Ten to $15 \mathrm{~d}$ after injection, the brains were sectioned to study tumor growth and the movement of tumor cells away from the main tumor mass into the underlying thalamus (Fig. 4). As in the in vitro assay, two independent lines for each transfectant were tested for invasion in vivo.

Intracranial grafts of 9L-GFP transfectants $(n=6)$ showed the same histological pattern reported previously for parental, untransfected 9L cells (Jaworski et al., 1996). That is, they grew as highly compact cell masses, with relatively smooth borders (Fig. $\left.4 A, A^{\prime}\right)$. Very few clusters of 9L-GFP cells were found distal to the boundary between the tumor and the underlying thalamus (Fig. 4 $A^{\prime}$, Table 1). In all of the sections from 9L-GFP tumors assayed, only two cell clusters were observed over $1 \mathrm{~mm}$ from the tumor border. The behavior of tumors resulting from $9 \mathrm{~L}$ $\mathrm{BEHAB} /$ brevican transfectants $(n=12)$ was indistinguishable from that of tumors resulting from 9L-GFP transfectants. The 
A

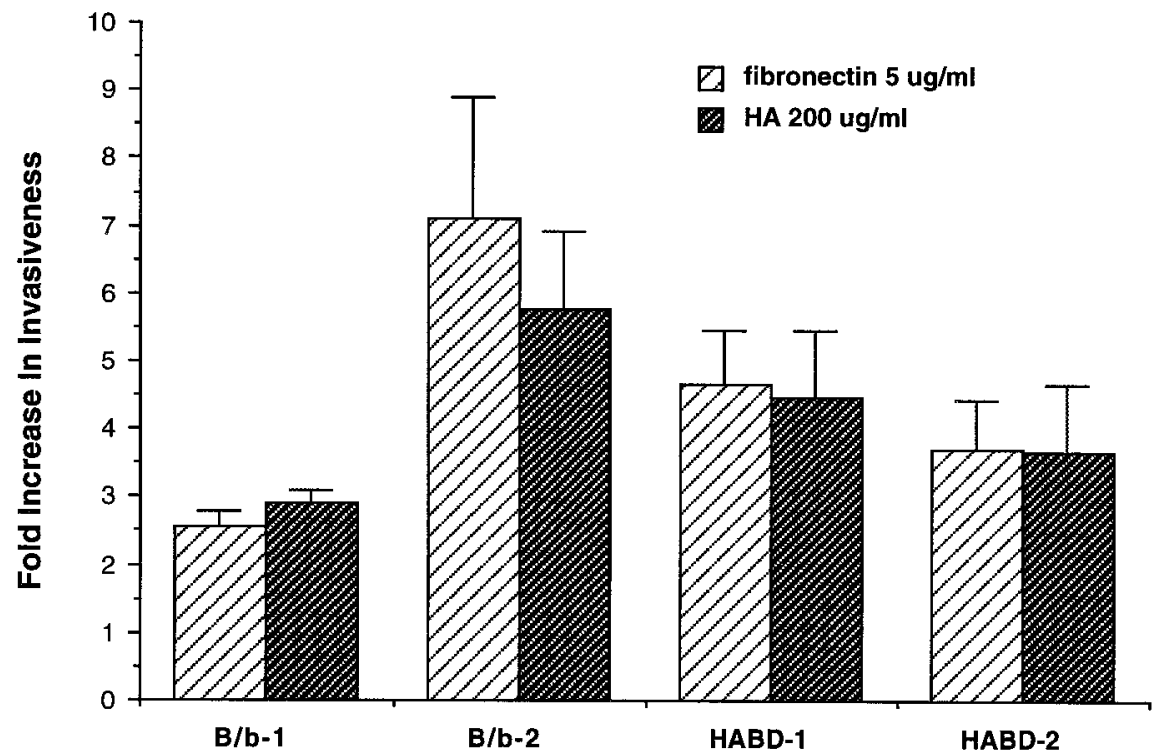

B

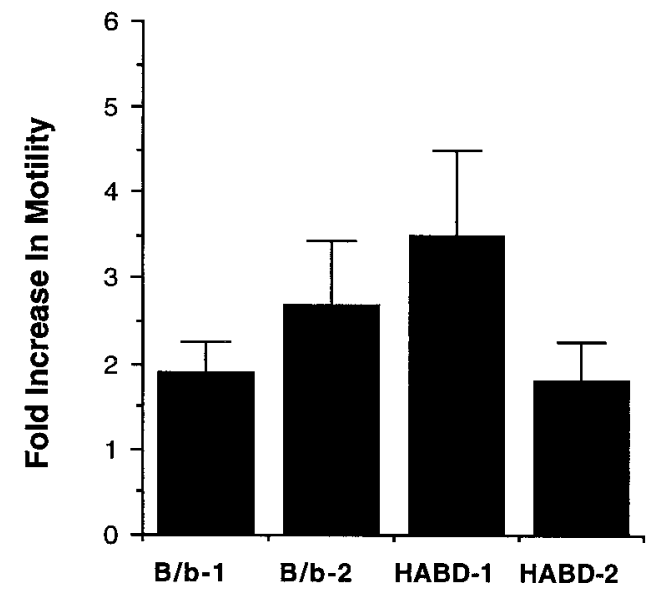

Figure 3. Full-length BEHAB/brevican and the HABD increase invasion and motility of $9 \mathrm{~L}$ cells in vitro. $A$, Invasion in the Matrigel invasion assay is potentiated by the expression of either full-length $\mathrm{BEHAB} /$ brevican or the HABD. Two independent cell lines for each of the constructs $(B / b-1$ and $B / b-2$ for $9 \mathrm{~L}-\mathrm{BEHAB} /$ brevican; $H A B D-1$ and $H A B D-2$ for 9L-HABD) were assayed for invasion in the Matrigel invasion assay (see Materials and Methods). Invasion is expressed relative to that observed for the 9L-GFP transfectants. Both constructs markedly increased invasion. Invasion was equivalent when either fibronectin or hyaluronan was the attractant in the lower chamber. $B$, Motility in the absence of Matrigel is also increased by the expression of either full-length $\mathrm{BEHAB} /$ brevican or the HABD. As seen in the Matrigel assay, both constructs similarly increased motility in a Matrigel-independent assay. The degree of invasion or motility seen for all four transfected cell lines was statistically different from 9L-GFP cells at the $p<0.01$ level. There was not a statistically significant difference between the behavior of $9 \mathrm{~L}$ $\mathrm{BEHAB}$ /brevican versus 9L-HABD transfectants. Error bar indicates SEM.
9L-BEHAB/brevican tumors also grew as compact cell masses, with few cell clusters located outside of the main tumor mass (Fig. $\left.4 B, B^{\prime}\right)$. Of the few clusters of cells that were observed beyond the border of the tumor with the underlying thalamus, almost all were located $0.5-1 \mathrm{~mm}$ from the tumor border (Table 1). Western blots of $9 \mathrm{~L}-\mathrm{BEHAB} /$ brevican tumors detected only the $140 \mathrm{kDa}$ fulllength protein (Fig. 5, lane 1). Therefore, although the expression of full-length $\mathrm{BEHAB} /$ brevican can increase the migration of 9L cells in an in vitro invasion assay, when tested in vivo, expression of the full-length protein does not confer on 9L cells the ability to migrate through normal adult brain matrix.

The lack of invasion by $9 \mathrm{~L}-\mathrm{BEHAB} /$ brevican transfectants in vivo, along with the demonstration of proteolytic cleavage products in human gliomas and invasive rat brain tumors, led us to test whether the HABD of BEHAB/brevican might mediate invasion in vivo. The behavior of 9L-HABD transfectants $(n=14)$ was markedly different from that of 9L-GFP and 9L-BEHAB/ brevican transfectants (Fig. $4 C, C^{\prime}$ ). In 9L-HABD experimental tumors, the border between the tumor and the underlying thalamus was interrupted by peninsulas of cells extending from the main tumor mass (Fig. $4 C^{\prime}$ ). In addition, there were numerous cell clusters $0.5-1.0 \mathrm{~mm}$ from the tumor border, with many cell clusters located over $1 \mathrm{~mm}$ from the main tumor mass (Table 1). Western blots of 9L-HABD tumor samples showed the presence of the 50-55 kDa HABD product (Fig. 5, lane 2). Therefore, expression of the $\mathrm{HABD}$ of $\mathrm{BEHAB} /$ brevican can increase the ability of $9 \mathrm{~L}$ cells to migrate through the brain matrix in vivo.

\section{DISCUSSION}

We show here that, within the brain, invasive ability can be conferred on a noninvasive glioma cell line by expression of an $\mathrm{N}$-terminal fragment of the $\mathrm{BEHAB} /$ brevican protein but not by expression of the full-length protein. Because partial proteolytic cleavage of the $\mathrm{BEHAB} /$ brevican protein occurs endogenously in both human and rodent invasive brain tumors, these results provide an explanation for glioma cell motility in the adult human brain. In addition, they suggest new therapeutic possibilities for human brain tumor.

Many studies have suggested a central role for extracellular matrix proteins in tumor growth and motility (Paulus et al., 1996; 
Figure 4. Intracranial tumors established from 9L-HABD, but not from 9L-BEHAB/brevican, cells show increased invasion into the surrounding brain. $A, A^{\prime}$, Intracranial tumors (asterisks) derived from 9L-GFP cells grow as compact cell masses, with little infiltration into the surrounding brain. The border with the underlying thalamus $\left(A^{\prime}\right)$ is smooth, with very few clusters of cells seen beyond the border between the tumor and the normal brain. $B$, $B^{\prime}$, Intracranial tumors (asterisks) derived from 9L-BEHAB/brevican cells showed identical behaviors to those of the control transfectants. These tumors also grew as compact cell masses, with little infiltration of the surrounding brain. Here again, very few cell clusters were observed in the normal brain adjacent to the tumor $\left(B^{\prime}\right)$. $C, C^{\prime}$, Intracranial tumors (asterisks) derived from 9L-HABD cells showed a marked increase in invasive ability compared with the other two cell lines. Although the main tumor mass was a compactgroup of cells, many cell clusters were

seen in the surrounding normal brain. The border of the 9L-HABD tumors with the underlying thalamus $\left(C^{\prime}\right)$ was often interrupted by peninsulas of cells extending out from the main tumor mass.

Table 1. Number and distance of tumor cell clusters from the main tumor mass

\begin{tabular}{lll} 
& $0.5-1.0 \mathrm{~mm}$ & $>1.0 \mathrm{~mm}$ \\
\hline 9L-GFP & $1.67 \pm 0.76$ & $0.33 \pm 0.33$ \\
9L-BEHAB/brevican & $1.69 \pm 0.77$ & $0.15 \pm 0.10$ \\
9L-HABD & $8.33 \pm 2.02$ & $8.75 \pm 3.70$
\end{tabular}

The number of cell clusters located $0.5-1 \mathrm{~mm}$ and over $1 \mathrm{~mm}$ from the main tumor mass was counted for all of the tumors in this experiment (one random section per tumor; $n=6$ independent tumors for 9L-GFP; $n=12$ for $9 \mathrm{~L}-\mathrm{BEHAB} /$ brevican; and $n=14$ for 9L-HABD). Two different transfected lines were used for each of the noncontrol transfectants. The HABD fragment markedly increased the number of cell clusters seen distant to the main tumor mass. The full-length BEHAB/brevican protein had no effect on cell infiltration into surrounding brain over that observed for the control 9L-GFP construct. The difference between the 9L-HABD versus the control 9L-GFP and 9L-BEHAB/brevican transfectants was statistically different at the $p<0.01$ level. Data shown here are the grouped averages of the number of cell clusters \pm SEM.

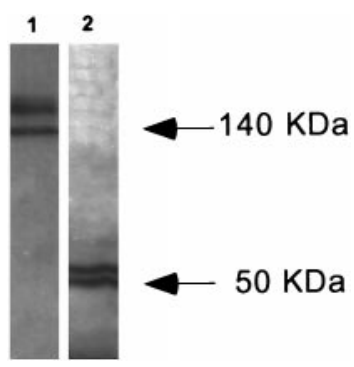

Figure 5. Intracranial tumors established from 9L-BEHAB/brevican and 9L-HABD cells express full-length or HABD proteins. Western blots of tumors produced after intracranial injection of $9 \mathrm{~L}-\mathrm{BEHAB} /$ brevican (lane 1) or HABD (lane 2) transfectants are shown. In 9L-BEHAB/ brevican tumors (lane 1), immunoreactivity for $\mathrm{BEHAB} /$ brevican is at $140 \mathrm{kDa}$. No evidence of a cleavage product is seen. In 9L-HABD tumors (lane 2), only a $50 \mathrm{kDa}$ product is observed.
Haugland et al., 1997; Merzak and Pilkington, 1997). HA and HA-binding proteins have been implicated in tumor metastasis (Knudson and Knudson, 1993; Entwistle et al., 1996). For example, the HA-binding protein RHAMM increases the metastatic potential of fibroblast cell lines (Hall et al., 1995). Our present results provide evidence that expression of the extracellular, HA-binding, BEHAB/brevican protein by invasive rodent and human brain tumors can increase the ability of glioma cells to invade into the surrounding normal brain.

Although both 9L-BEHAB/brevican and 9L-HABD cells showed an equivalent increase in invasive ability in the in vitro Matrigel invasion assay compared with control cells, only the 9L-HABD cells showed an increase in invasion when grown as intracranial grafts. Therefore, an increase in invasive ability observed in the Matrigel assay did not necessarily predict an increase in invasive ability in the brain. One explanation for the invasive behavior of 9L-BEHAB/brevican cells in Matrigel, but not in the brain, is that glioma invasion requires proteolysis of the $\mathrm{BEHAB} /$ brevican protein, and the Matrigel might contain the necessary proteases. Our results indicate that proteolysis is not likely to be responsible for the migration of 9L-BEHAB/brevican cells through Matrigel. First, heat inactivation of the Matrigel, which should inactivate protease activity, did not alter the invasive ability of 9L-BEHAB/brevican transfectants. Second, 9L$\mathrm{BEHAB} /$ brevican cells also migrated in a Matrigel-free motility assay. Therefore, it is unlikely that cleavage of the protein explains the motility of the 9L-BEHAB/brevican transfectants in the in vitro assays. A more likely explanation is that, whereas the full-length BEHAB/brevican protein can increase invasion and motility on extracellular matrix elements of non-neural origin, it does not increase invasion or motility on the extracellular matrix of the brain. This result suggests that caution be exercised in the interpretation of results from in vitro assays, because the behavior of cells in in vitro assays may not accurately predict the behavior of cells in vivo. A similar discrepancy has been reported for other tumor cell types, in which increased invasiveness in a Matrigel assay was not paralleled by increased invasiveness in vivo (Noel et 
al., 1991). Invasion through normal brain tissue may be particularly difficult to model in vitro because of the unusual and heterogeneous composition of the extracellular matrix of the brain (Lander et al., 1997).

In the normal adult human brain, the level of BEHAB/brevican expression is extremely low. In the normal adult rat brain, however, BEHAB/brevican is expressed at easily detectable levels (Jaworski et al., 1994; Yamada et al., 1994; Yamaguchi, 1996). It is important to note that, although cells in the rat brain surrounding an invasive tumor express $\mathrm{BEHAB} /$ brevican, the level of expression by invasive tumors (such as those derived from either C6 or CNS-1 glioma cells) is markedly higher than that in the surrounding normal brain (Jaworski et al., 1996). Therefore, the level of cleaved BEHAB/brevican in the surrounding brain may not be sufficient to permit invasion by the 9L-GFP or full-length 9L-BEHAB/brevican transfectants. Alternatively, invasion may require expression of $\mathrm{BEHAB} /$ brevican by the tumor cells themselves, perhaps involving an interaction of the cleavage product(s) with the glioma cell surface (Yamada et al., 1997). Although expression of an N-terminal HABD fragment of BEHAB/ brevican clearly increases the invasive ability of 9L cells, the pattern of invasion of 9L-HABD transfectants does not fully mimic that of the highly invasive CNS-1 and C6 cell lines (Jaworski et al., 1996), suggesting that additional molecules may act to facilitate glioma invasion further.

The BEHAB/brevican gene is expressed as two isoforms, one secreted and one GPI-linked (Seidenbecher et al., 1995). In the normal rat brain (Seidenbecher et al., 1995) and in human brain tumors (J. Gaw, V. Chang, and S. Hockfield, unpublished observations), the GPI-linked form is expressed at very low levels compared with the secreted form. The role, if any, of the GPIlinked form in tumor invasion is currently under investigation. The most important modification of the BEHAB/brevican protein product for cell invasion appears to be cleavage into the $\mathrm{N}$-terminal fragment containing an HABD and the C-terminal fragment. A predicted site for proteolytic cleavage of BEHAB/ brevican has been mapped and is highly conserved with a proteolytic site of another ECM protein, aggrecan (Yamada et al., 1995; Yamaguchi, 1996). The observations that BEHAB/brevican is cleaved in invasive human and rodent tumors and that fulllength $\mathrm{BEHAB} /$ brevican does not mediate invasion in vivo together indicate that proteolytic cleavage is required for invasion. Moreover, cleavage of the protein appears to require an association of the protease activity with the cell that expresses the protein, because the protein produced by $9 \mathrm{~L}-$ full-length transfectants remains uncleaved (Fig. 5, lane 1), whereas the endogenous $\mathrm{BEHAB} /$ brevican expressed in the surrounding brain is cleaved.

The results presented here are consistent with a twocomponent mechanism for brain tumor cell invasion: first, an upregulation in the expression of $\mathrm{BEHAB} /$ brevican by glioma cells, followed by the cleavage of the protein into N-terminal HABD and C-terminal fragments. Earlier work from our laboratory indicates that expression of $\mathrm{BEHAB} /$ brevican by glioma cells is regulated by a brain-derived factor (Jaworski et al., 1996). When maintained under standard cell culture conditions or when grown as subcutaneous grafts outside of the brain, none of the 19 glioma cell lines we have tested expresses BEHAB/brevican. When glioma cell lines are grown as intracranial grafts, however, cell lines that grow with an invasive phenotype characteristic of human glioma are induced to express BEHAB/brevican. Cell lines that grow as noninvasive intracranial tumors do not express the gene. The identity of the $\mathrm{BEHAB} /$ brevican-inducing factor has yet to be determined but appears to be a soluble, brainspecific factor. In addition, the results presented here provide evidence of a second required component, a protease that cleaves $\mathrm{BEHAB} /$ brevican, the identity of which we are currently pursuing. Candidate proteases include the matrix metalloproteinases expressed in gliomas (Merzak and Pilkington, 1997), for which $\mathrm{BEHAB} /$ brevican is a possible substrate. Regulated cleavage of extracellular matrix proteins may be a general mechanism for the control of cell motility; recent studies have demonstrated that cleavage of laminin-5 is required for breast epithelial cell migration (Giannelli et al., 1997) and that inhibition of matrix metalloproteinase activity during embryogenesis blocks myoblast migration into the tongue (Chin and Werb, 1997).

The aggressive invasion by malignant glioma into the surrounding normal brain makes brain tumors highly refractory to regional therapies, such as surgery or focal irradiation. BEHAB/brevican is expressed with unprecedented specificity in glioma and presents a novel potential target for the treatment of malignant primary brain tumor. Here, we have shown that invasion by glioma cells into normal brain is potentiated by a cleavage product of $\mathrm{BEHAB} /$ brevican. In addition to targeting the BEHAB/ brevican gene or its products, the present work suggests another therapeutic target, the protease responsible for the cleavage of $\mathrm{BEHAB} /$ brevican. BEHAB/brevican is brain-specific and is expressed at almost undetectable levels in the normal adult human brain; targeted disruption of either the expression or the proteolytic cleavage of $\mathrm{BEHAB} /$ brevican would be predicted to have minimal deleterious consequences on normal brain tissue. Functional inhibition of $\mathrm{BEHAB} /$ brevican might slow the migration of tumor cells from the original tumor site(s), thereby increasing the efficacy of regional therapies.

\section{REFERENCES}

Albini A, Iwamoto Y, Kleinman HK, Martin GR, Aaronson SA, Kozlowski JM, McEwan RN (1987) A rapid in vitro assay for quantitating the invasive potential of tumor cells. Cancer Res 47:3239-3245.

Chin JR, Werb Z (1997) Matrix metalloproteinases regulated morphogenesis, migration and remodeling of epithelium, tongue skeletal muscle and cartilage in the mandibular arch. Development 124:1519-1530.

Entwistle J, Hall CL, Turley EA (1996) HA receptors: regulators of signalling to the cytoskeleton. J Cell Biochem 61:569-577.

Giannelli G, Falk-Marzillier J, Schiraldi O, Stetler-Stevenson WG, Quaranta V (1997) Induction of cell migration by matrix metalloprotease-2 cleavage of laminin-5. Science 277:225-228.

Hall CL, Yang B, Yang X, Zhang S, Turley M, Samuel S, Lange LA, Wang C, Curpen GD, Savani RC, Greeberg AH, Turley EA (1995) Overexpression of the hyaluronan receptor RHAMM is transforming and is also required for $\mathrm{H}$-ras transformation. Cell 82:19-28.

Haugland HK, Tysnes BB, Tysnes O-B (1997) Adhesion and migration of human glioma cells are differently dependent on extracellular matrix molecules. Anticancer Res 17:1035-1045.

Herndon ME, Lander AD (1990) A diverse set of developmentally regulated proteoglycans is expressed in the rat central nervous system. Neuron 4:949-961.

Hockfield S (1990) Proteoglycans in neural development. Semin Dev Biol 1:55-63.

Hockfield S, McKay R (1985) Identification of major cell classes in the developing mammalian nervous system. J Neurosci 5:3310-3329.

Hockfield S, Zaremba S, Kalb RG, Fryer H (1990) Expression of neural proteoglycans correlates with the acquisition of mature neuronal properties in the mammalian brain. Cold Spring Harb Symp Quant Biol 55:505-514

Jaworski DM, Kelly GM, Hockfield S (1994) BEHAB, a new member of the proteoglycan tandem repeat family of hyaluronan binding proteins, is restricted to the brain. J Cell Biol 125:495-509.

Jaworski DM, Kelly GM, Hockfield S (1995) The CNS specific hyaluronan-binding protein, $\mathrm{BEHAB}$, is expressed in ventricular zones coincident with gliogenesis. J Neurosci 15:1352-1362. 
Jaworski DM, Kelly GM, Piepmeier JM, Hockfield S (1996) BEHAB (brain enriched hyaluronan binding) is expressed in surgical samples of glioma and in intracranial grafts of invasive glioma cell lines. Cancer Res 56:2293-2298.

Knudson CB, Knudson W (1993) Hyaluronan-binding proteins in development, tissue homeostasis, and disease. FASEB J 7:1233-1241.

Koochekpour S, Pilkington GJ, Merzak A (1995) Hyaluronic acid/ $\mathrm{CD} 44 \mathrm{H}$ interaction induces cell detachment and stimulates migration and invasion of human glioma cells in vitro. Int J Cancer 63:450-454.

Lander CE, Hockfield S (1998) The extracellular matrix of the peripheral and central nervous systems. In: Encyclopedia of neuroscience (Adelman G, Smith B, eds). Amsterdam: Elsevier, in press.

Lander CE, Kind P, Maleski M, Hockfield S (1997) A family of activitydependent neuronal cell-surface chondroitin sulfate proteoglycans in cat visual cortex. J Neurosci 17:1928-1939.

Merzak A, Pilkington GJ (1997) Molecular and cellular pathology of intrinsic brain tumours. Cancer Metastasis Rev 16:155-177.

Merzak A, Koochekpour S, Pilkington GJ (1994) CD44 mediates human glioma cell adhesion and invasion in vitro. Cancer Res 54:3988-3992.

Mohanam S, Sawaya R, McCutcheon I, Ali-Osman F, Boyd D, Rao JS (1993) Modulation of in vitro invasion of human glioblastoma cells by urokinase-type plasminogen activator receptor antibody. Cancer Res 53:4143-4147.

Noel AC, Calle A, Emonard HP, Nusgens BV, Simar L, Foidart J, Lapiere CM, Foidart J-M (1991) Invasion of reconstituted basement membrane matrix is not correlated to the metastatic cell phenotype. Cancer Res 51:405-414.

Paulus W, Baur I, Beutler AS, Reeves SA (1996) Diffuse brain invasion of glioma cells requires beta-1 integrin. Lab Invest 75:819-826.

Seidenbecher CI, Richter K, Rauch U, Fassler R, Garner CC, Gundelfinger ED (1995) Brevican, a chondroitin sulfate proteoglycan of rat brain, occurs as secreted and cell surface glycosylphosphatidylinositolanchored isoforms. J Biol Chem 270:27206-27212.

Sheppard AM, Hamilton SK, Perlman AL (1991) Changes in distribution of extracellular matrix components accompany early morphogenetic events of mammalian cortical development. J Neurosci 11:3928-3942.

Yamada H, Watanabe K, Shimonaka M, Yamaguchi Y (1994) Molecular cloning of brevican, a novel brain proteoglycan of the aggrecan/versican family. J Biol Chem 269:10119-10126.

Yamada H, Watanabe K, Shimonaka M, Yamasaki M, Yamaguchi Y (1995) cDNA cloning and the identification of an aggrecanase-like cleavage site in rat brevican. Biochem Biophys Res Commun 216:957-963.

Yamada H, Fredette B, Shitara K, Hagihara K, Miura R, Ranscht B, Stallcup WB, Yamaguchi Y (1997) The brain chondroitin sulfate proteoglycan brevican associates with astrocytes ensheathing cerebellar glomeruli and inhibits neurite outgrowth from granule neurons. J Neurosci 17:7784-7795.

Yamaguchi Y (1996) Brevican: a major proteoglycan in adult brain. Perspect Dev Neurobiol 93:307-317. 